\title{
PROBIOTICS AND ORAL HEALTH: A REVIEW
}

\author{
${ }^{1}$ Dr. Amol Jamkhande (Corresponding Author) ${ }^{2}$ Dr. Saurabh Kakade ${ }^{3}$ Dr. Aishwarya Gundawar \\ ${ }^{1}$ Associate Professor - Dept of Public Health Dentistry Bharati Vidyapeeth Dental College \& Hospital Pune. India \\ ${ }^{2}$ Assistant Professor - Dept of Public Health Dentistry Bharati Vidyapeeth Dental College \& Hospital Pune India \\ ${ }^{3}$ Intern - Dept of Public Health Dentistry Bharati Vidyapeeth Dental College \& Hospital Pune. India
}

DOI: http://dx.doi.org/10.47937/SJCMDS.2021.1102

\begin{abstract}
Probiotics are non-pathogenic living microbes used to treat several medical conditions. They have been added in a few food products due to their favourable results on human health. The mechanism of action of probiotics is associated with their capacity to cope with pathogenic microorganisms for adhesion sites, to antagonize these pathogens or to regulate the host's immune response. Probiotics might be helpful in intercepting and treating oral infections, including dental caries, periodontal disease and halitosis. Probiotics contribute to a healthy microbial balance by interacting with oral micro biome which impacts the general health, being a significant contributor to oral health. The development of drug resistance and the side effects of available antimicrobials have confined their use in an array of prophylactic options. Currently, no such evidence exists to support the use of probiotics to prevent, treat or manage oral cavity diseases. Probiotics don't have any adverse effects and there is no evidence of being used for the treatment or as a preventive measure for the oral health. In this review, author tried to explore the use of probiotics in prevention, treatment and management of oral cavity diseases and the possibilities of developing designer probiotics for the next generation of oral healthcare.
\end{abstract}

Keywords: Probiotics; Lactobacillus; Dental healthcare; Periodontics.

\section{INTRODUCTION}

The oral cavity is made up of 700 bacterial species or phylotypes, of which over $50 \%$ have not been cultivated. (1)The dietary benefit of microorganism has a long history. Farm products like kefir, koumiss, liben and curd, were frequently used before the existence of microorganism was acknowledged. Facts concerning the significance of farm products is found in the bible and the Bhagavad Gita ${ }^{(8}$ ) For over a number of years, few probiotic bacterium have been added to food products because of their valuable addition to the health of the living beings. ${ }^{(2)}$ The optimistic outcomes of probiotics in general health have resulted in their outspread. Primary use of probiotics focuses on managing the intestinal tract problems. ${ }^{(4)}$ The word probiotics originates from a Greek word meaning "for life." The Food and Agricultural Organisation of the United Nations (FAO)/WHO in 2001 defined probiotics as "live microorganisms, when administered in adequate amounts; confer a health benefit to the host." (5), (6), (7) Probiotics are a positive influence on animals and human health. In 1994, the World Health Organisation (WHO) stated probiotics as the upcoming most important immune defense system when regularly prescribed antibiotics are rendered meaningless. ${ }^{(3)}$ Use of lactic acid bacilli in health through regular ingestion was proposed by Ukrainian bacteriologist Ilya Metchnikaff in 1908. In 1950, a probiotic product was rubbed on pigs' skins for cleaning purpose. (2) In 1965, Lilley and Stillwell established the word probiotics as an opposite to antibiotics. In 1974, Mann and Spoering noticed the reduction of blood serum cholesterol levels by use of fermented yogurt. ${ }^{(8)}$ Hull in 1984 discovered the first probiotic species, the Lactobacillus biodum.(8) Numerous clinical researches have proven their usefulness in treating cancer and dental caries ${ }^{(8)}$ The purpose of diet in health and well-being is universally acknowledged. Progress in nutritional science has intended towards apprehending the physiological effects of diet apart from the nutritional effect.Probiotics are the subject of a widespread research in food and nutritional science including oral health.

\section{Probiotics are provided in products in one of the following basic ways:}

1) A culture concentrate which is added to a beverage or food, for example, fruit juices.

2) Infused into prebiotic fibres.

3) Added into a milk-based food, for example, dairy products such as milk, milk shakes, yogurt, cheese, kefir, and bio drink sauerkraut, kvass, natto, kombucha. [Figure 1]

4) As concentrated and dried cells packaged as dietary supplements (non-dairy products) such as powder, capsule, and gelatin tablets. (10), (11) 


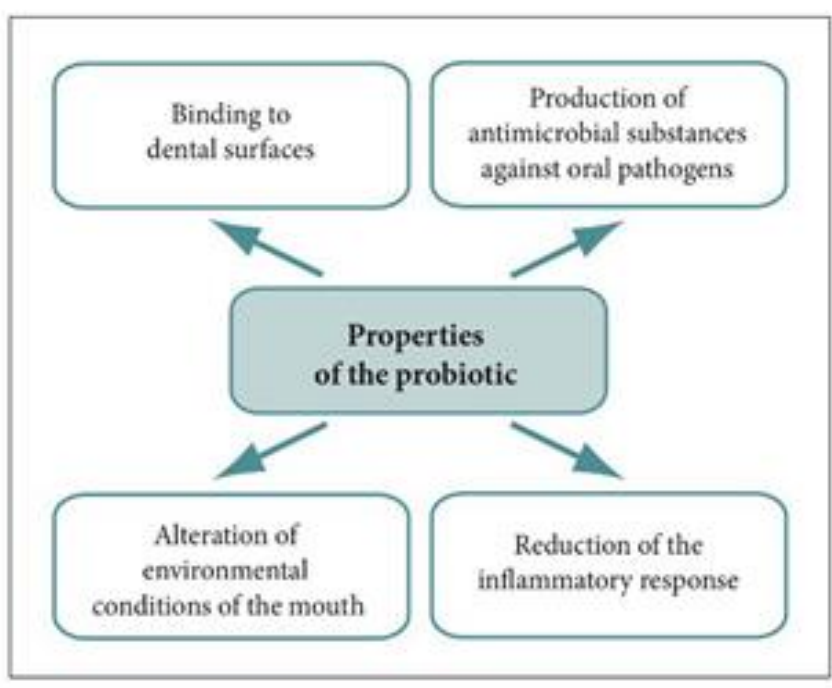

Figure 1: Ideal Properties of a probiotic intended for use in disorders of the mouth

\section{COMPOSITION OF PROBIOTICS:}

Probiotics can be yeast, bacteria or moulds. Most commonly they are bacteria. Some of these bacterial species are:

-Lactic acid producing bacteria (LAB): Lactobacillus, Bifidobacterium, Streptococcus.

- Non Lactic acid producing bacteria (LAB) species: Bacillus, Propionibacterium

- Non-pathogenic yeasts: Saccharomyces

- Non spore forming and non-flagellated rod or Coccobacilli ${ }^{(12)}$

\section{CHARACTERISTICS OF PROBIOTICS:}

Probiotics are living microorganisms, safe for consumption, which have a beneficial effect in health. A fully characterized bacterial strain can be called a probiotic. The FAO and the WHO have advised that probiotic bacterial strains should be distinguished by their ability of resistance to antibiotics and haemolytic activities, their capacity to produce toxins, their infectious power in immuno compromised animal models and their side effects in human beings. These probiotics strains should be submitted to randomized clinical trials. The outcome of such studies should indicate betterment of health. (2)

\section{MECHANISM OF ACTION OF PROBIOTICS:}

Mechanisms to be explained how probiotics are (Fig. 1). For example, these bacteria secrete different antimicrobial substances like organic acids, hydrogen peroxide and bacteriocins. ${ }^{(70)}$ In addition, they compete with pathogenic agents for adhesive sites on the mucosa. (68) (71) Probiotics can change the surrounding environment by regulating the $\mathrm{pH}$ and/or the oxidation-reduction potential, which may compromise the ability of pathogens to become established. Finally, probiotics may yield valuable results by stimulating nonspecific immunity and regulating the humoral and cellular immune response. ${ }^{(72)}$ A combination of probiotics is often used to increase beneficial effects. ${ }^{(69)}$

\section{CHARACTERISTICS OF CLASSIC PROBIOTIC MICROORGANISMS}

1) Must restore and endure the intestinal micro flora.

2) Must adhere to the intestinal mucosa or the target tissue.

3) Must be ready to survive and metabolize in the gut environment, for example: Defiance to low $\mathrm{pH}$.

4) Should have useful result on host animal.

5) Must be viable under storage for longer duration.

6) Should be safe for human consumption and beneficial physiological effects should be scientifically demonstrable

7) Must be non-pathogenic and non- toxic.

8) Should be stable in acidic and alkaline environments.

9) Must be bacteriologically distinguished and shall have put.

\section{PROBIOTICS AND PERIODONTOL DISEASES:}

Periodontal diseases are- Gingivitis and Periodontitis

Gingivitis is defined as inflammation bounded to the unconnected gingiva, while periodontitis is a developing cataclysmic infection that attacks all the supportive tissues of the teeth as well as the alveolar bone. The primary microorganisms related with periodontitis are Porphyromonasgingivalis, Treponemadenticola, Tannerella forsythia, and Aggregatibacteractinomycetecomitans. (17), (18) The chief constituents for the forming of periodontal diseases are bacteria in supra and sub-gingival biofilms. Mucosal immune outcomes may be summoned by prebiotic booster dose. Their projected mechanism is building up a mucosal barrier via topical effects on the epithelium, and stimulation of both the innate and adaptive immune systems. A decrement in gum bleeding and faded gingival infection is been determined by Krasse et al. with the consumption of L reuteri, (19) Caglar E et al used L. reuteri containing bubble gums in 42 robust patients and evaluated the repercussions on the crevicular fluid volume(interleukin-1ß, interleukin-6, interleukin-10, and tumour necrosis factor-alpha $[\mathrm{TNF}-\alpha]$ ), cytokine levels and bleeding on probing.He found crevicular fluid volume, the levels of TNF- $\alpha$ and interleukin-8 and bleeding were all remarkably decreased.(17) As stated by KollKlais et al. probiotics consisting of Lactobacillus effected an $82 \%$ and $65 \%$ suppression in the development of P. gingivalis and Prevotellaintermedia.Riccia et al. utilized lozenges into whichL. brevis was integrated to study its anti-inflammatory effects in a set of patients having chronic periodontitis.

The report demonstrated momentous refinement, in plaque index, gingival index, bleeding on probing and remarkable reduction of inflamed gingiva. (20) Probiotic stains enclosed in periodontal dressings in ideal concentration of $108 \mathrm{CFU} / \mathrm{mL}$ have been shown 
to lessen the number of constant stray periodontal pathogens: Bacteroides spp., Actinomyces spp., and S. intermedius and also Candida albicans. ${ }^{(22)}$ Probiotic microorganisms might favour periodontal health and might also colonize a gingival pocket after scaling and root planing provided they are capable of launching themselves in the oral micro flora. Nevertheless additional longitudinal studies are needed to support these findings.

\section{PROBIOTICS AND DENTAL CARIES:}

Dental caries is a multi-step disease of bacterial derivation that is defined by acid demineralization of the tooth enamel. (23-25) Streptococcusmutans is a chief activating microorganism for caries. Raised amount of streptococcus counts are connected with increased escalated fear of dental caries. (24-26) Toeliminate cariogenic bacteria present on the teeth surface to sustain against dental caries, firstly a probiotic microorganism should match the dental surface and combine into the bacterial community creating biofilms. Secondly, they should become a constituent of the biofilm which forms on the tooth surfaces and finally they should compete with cariogenic bacteria. All of this assists to reduce the cariogenic bacterial growth levels. (24-27) Nikawa et al. reported that intake of yogurt containing Lactobacillus reuteri over a period of 15 days dilutes S. mutans in the saliva by $80 \%$. Proportionate outcomes were acquired by integrating probiotics in bubble gums or lozenges. ${ }^{25)}$ Probiotics incorporated in milk products neutralize acidity. For example, it has been observed that cheese forbids demineralization of the enamel and promotes its remineralisation. ${ }^{(28,29)}$ In survey like Näse L and Meurman JH, single strain of Lactobacillus rhamnosus and the species Lactobacillus casei prohibited in vitro maturation of both the cariogenic streptococci, i.e. S. mutans, and S. sobrinus. (30), (31) Lately, Petti et al. observed that yogurt consisting of Streptococcus thermophilus and Lactobacillus bulgaricus have selective bactericidal effects on streptococci of the mutans group. Lately clinical studies have exhibited the day-to-day consumption of yogurt, milk, or cheese consisting probiotics led to a drop-off in the amount of cariogenic streptococci in the saliva and a diminution in dental plaque (17), (25), (29), (32), (33) In 2001, Näse et al. published the survey of an 1.5 years of study of 594 children of 16 years which demonstrated their effects on dental caries of consumption of milk along with a strain of L. rhamnosus.They reached a conclusion that children who drink milk consist of this probiotic especially those who are 3-4years old, had fewer dental caries and lower salivary counts of S.

\section{PROBIOTICS IN ORAL HALITOSIS:}

Oral malodor is a state which may impede the social life and selfesteem of an individual. Extensive approval for probiotic interference providing health benefits for non-intestinal body sites, application of it on alternative target tissues has increased, to obtain more specific and enduring benefits. Different studies have revealed the role of probiotic which help to decrease inflammation of gingiva. Nevertheless, the survey of a stronger proof regarding the role of probiotics in treating and preventing oral malodor is less. ${ }^{(34)}$

\section{PROBIOTICS AND CANDIDIASIS:}

Candida albicans amongst all is the most frequent infectious agent present in the oral flora. Eating probiotic cheese consisting L. rhamnosus GG and Propionibacterium freudenreichii ssp. Shermanii JS has shown a decrease in C albicans count. ${ }^{(64)}$

\section{DISCUSSION:}

Several mechanism have been proposed to justify how probiotics works. For instance, these bacteria stimulate numerous antimicrobial substances such as organic acids hydrogen peroxide, and bacteriocins. ${ }^{(35)}$ Also their challenge is with pathogens for adhesive sites on the mucosa. In addition, probiotics also alter the surrounding environment by regulating the $\mathrm{pH}$ and/or the oxidation-reduction prospect which might square off the capability of pathogens to become habituated. In the end, probiotics might provide advantageous effects by stimulating nonspecific immunity and regulating the humoral and cellular immune response. An association of probiotic strains is frequently used to gain these advantageous effects. ${ }^{(36)}$ The utilization of probiotics by human beings is almost entirely concentrated on obtaining the effects through the consumption of microorganisms primitively derived from intestinal sources. ${ }^{(37)}$ The bacteria in milk and milk products comprises of the most important sources of probiotics for humans. (38) Most of the probiotic bacteria are a part of genera Lactobacillus, Bifidobacterium, Propionibacterium, and Streptococcus. ${ }^{(39),(40),(41)}$

Various studies have shown the effectivity of certain probiotics in treating systemic and infectious diseases. Probiotics are largely used for "healthy gut." Nonetheless, the notion of alternative target sites has emerged ${ }^{(42)}$ Bernaola Aponte et al. in a survey inferred that there were limited grounds saying that probiotics can be beneficial in treating persistent diarrhoea in children. ${ }^{(43)}$ Goldenberg et al. in a review declared that probiotic was both secure and efficient for avoiding clostridium difficile-associated diarrhoea. ${ }^{(45)}$ Hao et al. discovered in their study on probiotics which aimed to prevent acute upper respiratory tract infection (URTI) that probiotics were found to be better than placebo in decreasing the number of candidates experiencing episodes of acute URTI by about $47 \%$ and the time span of an episode of acute URTI by about 1.89 days and might slightly decrease the antibiotic use, also side effects of probiotics were minor and gastro intestinal symptoms were the most common. ${ }^{\left({ }^{46}\right)}$ Then the concept of application of probiotic therapy in oral health was introduced. Apart from the use of probiotics in treating and preventing gastrointestinal tract infections, there have been studies performed to test the efficacy in the treatment and prevention of dental caries and periodontal diseases. (46), (47) Yanine et al. in their review declared that the benefit of probiotics on the prevention and treatment of periodontal diseases is debatable. ${ }^{(48)}$ The oral microflora is dwelling with a variety of bacterial species that produce numerous fetid substances as a result of protein degradation VSC 
(volatile sulphur compound)-producing bacteria colonizing the dorsum of the tongue have recently been implied in oral malodour. Detection of VSCs, like methylmercaptan and hydrogen sulfite, through organoleptic and objective methods, can assist in the identification of their source. Following comprehensive evaluation for possible causes, most halitosis in patients seen in an ear,nose, and throat or dental practice can be localized to the tongue. (49), (50) Bacteriologic analysis of biofilm and scraped specimens obtained from the lingual dorsum and other oralsites, primarily gingival pockets and tonsillar crypts can identify VSC producing bacteria. Porphyromonas, Prevotella, Actinobacillus, and Fusobacterium species are the most common identified organisms. ${ }^{(51)}$ Halitosisarising from the lingual dorsum secondary to overpopulated VSC-producing bacteria can be properly managed with a collection of mechanical cleansing using tongue brushes or scrapes and chemical solutions containing essential oils, zinc chloride, and cetylpyridinium chloride. (52), (53), ${ }^{(54)}$ Using of mouthwash and doing dental treatments gives a shortterm relief. Antimicrobial treatment randomly use up populations of both the problematic bacteria and those bacteria that are not thought to be implied in halitosis, but which might be essential in maintaining the normal oral micro-flora. The consequence of antimicrobial treatment is necessarily only a short-term decrease in malodour, until the halitosis-causing bacteria become reestablished. Hence, probiotic therapy was used for treating halitosis (55) Few problems occurred while performing the analysis, first, the types of pro-biotic studied varied throughout the trials, second and the most important issue, the variables were not reported decently in some of the surveys. Information on the outcomes of interest was only found in graphs and tables which did not allow acquiring the exact value of the final measurement in each group. (58), (59), (61), (62), (63)

Only 11 studies contributing to the results and conclusions are a very small number when compared to a large number of population affected due to oral malodour. All the surveys are of shortened time-span varying from 1-98 days. Therefore, do not shed light over the prevention aspect of probiotics over halitosis. It still lacks the evidence even though some studies have showed remarkable reduction in the halitosis levels as in two pilot studies which have decided that there was a remarkable reduction in the organoleptic scores and in production of the VSCs. A randomized clinical trial used commercially available probiotic drink, Yakult, as a vehicle of administration of probiotic, revealed no broad ecologic changes in the mouth and no noticeable effects on the halitosis levels, thus concludes that simply oral ingestion of probiotic has no effect on halitosis. ${ }^{(56),(57)}$ Given the large number of internet sites devoted to the sale of probiotic products to people with oral malodour, one would expect that there are many well supported scientific claims of the effectiveness of these products. In reality, there are only countable few trials performed to assess the effectiveness of probiotics in the treatment of halitosis. There are various studies which have made use of probiotics in adjunct with other oral prophylactic products, but exclusive use of probiotics is scarce. In spite the limitations, we believe that this is the best possible summary of evidence of the topic. We advised conducting trials with appropriate sample sizes to have enough power to detect the differences among the groups and further extensive studies to find out the potential of the probiotics in the prevention of malodour. ${ }^{(60)}$

\section{SAFETY MEASURES:}

Due to enhanced probiotics supplementation of different food products, safety measures are a leading concern. Probiotics are frequently regulated as dietary supplements instead of pharmaceutical or biological products. As a safety measure, probiotic microorganisms should not be pathogenic, should not have any maturation stimulating effects on bacteria causing diarrhoea, should not have an ability to transfer antibiotic resistance genes, and should not cause sepsis or bacteraemia. The probiotic should hold genetic stability in oral micro flora. Several events from antibiotic susceptibility tests claim that the tet- (W) and tet- (S) genes in some probiotic Lactobacilli and Bifidobacterium strains are accountable for sulfamethoxazole, gentamycine, polymyxin B and tetracycline resistance. These collection show the need of minimal safety rating during the selection of strains for probiotic use. ${ }^{(65),(66)}$

\section{FUTURE APPLICATION:}

Various applications of probiotics in general health can gain its demand. In future, probiotics can be used to cure many health issues. The important steps in many applications will be to make products available that are safer and clinically evidenced in a particular formulation, which should be easily available to physician and consumers. In India, sporolac i.e., Sporolacto bacilli is a normally used probiotic. Lately, Bacillus mesentricus is used as an alternative to B-complex. ${ }^{(67)}$ Genetically enhanced lactic acid bacteria has been proposed as a vehicle to deliver vaccines in the gastrointestinal tract. (64) Nanotechnology of probiotics is an area of emerging interest and opens up whole new possibilities for the probiotics use. Their applications to the agriculture and food sector are comparatively new compared with their use in drug delivery and pharmaceuticals. The basic of probiotic nanotechnology applications is presently in the development of nano-encapsulated probiotics. The nano structured food ingredients are being formed with the claims that they offer better taste, texture and consistency. Applications of nanotechnology in organic food production require safeguard, as little is known about their impact on environment and human health. In few recent food applications of nanotechnology, safety and risk problems of nano materials, routes for nano particles entering the body, existing regulations of nanotechnology in various countries, and lack of authorization system of nano products were reported $(73,74)$.

\section{REFERENCES:}

1. Aas JA, Paster BJ, Stokes LN, Olsen I, Dewhirst FE. Defining the normal bacterial-flora of the oral cavity. J ClinMicrobiol 2005; 43:5721-32.

2. Bonifeit L, Chandad F, Grenier D. Probitics for oral health: Myth or reality? JCDA. 2009; 75:585-90.

3. Narang S, Gupta R, Narang A. Probitics in oral health care- A review. Int J SciEng Res 2011; 2:1-5.

4. Flichy-Fernández AJ, Alegre-Domingo T, Peñarrocha-Oltra D, 
Peñarrocha-Diago M. Probiotic treatment in the oral cavity: An update. Med Oral Patol Oral Cir Buccal 2010; 15:e677-80.

5. Reddy RS , Swapna LA, Ramesh T, Singh TR, Vijayalaxmi N, Lavanya R. Bacteria in Oral Health - Probiotics and Prebiotics A Review. Int J Biol Med Res 2011; 2:1226-33.

6. Bosch M, Nart J, Audivert S, Bonachera MA, Alemany AS, Fuentes $\mathrm{MC}$, et al. Isolation and characterization of probiotic strains for improving oral health. Arch Oral Biol 2012; 57:539-49

7. Hasslof P, Hedberg M, Twetman S, Stecksen-Blicks C. Growth inhibition of oral Mutans streptococci and Candida by commercial probiotic lactobacilli - An in vitro study. BMC Oral Health 2010; 10:2-6.

8. Saraf K, Shashikanth MC, Priya T, Sultana N, Chaitanya NC. Probiotics - Do they have role in medicine and dentistry? J Assoc Physicians India 2010; 58:488-92.

9. Babaji P, Keswani K, Lau H, Lau M, Sharma N, Punga R. Role of probiotics in oral health: A review of the literature. J Educ Ethics Dent 2012; 2:52-5

10. Reddy JJ, Sampathkumar N, Aradhya S. Probiotics in dentistry: Review of the current status. Rev ClínPesqOdontol 2010; 6:261-7.

11. Singh T, Majumdar S, Ghosh AK, Pal SP, Waghle SR, Dakchiyani MB. Probiotics in oral health: A review. J Adv Med Dent Sci Res 2014; 2:62-5.

12. Caglar E, Kargul B, Tanboga I. Bacteriotherapy and probiotics' role on oral health. Oral Dis 2005; 11:131-7.

13. Pradeep K, Kuttappa MA, Prasana KR. Probiotics and oral health: An update. SADJ 2014; 69:20-4.

14. Babaji P, Keswani K, Lau H, Lau M, Sharma N, Punga R. Role of probiotics in oral health: A review of the literature. J Educ Ethics Dent 2012; 2:52-5.

15. Parvez S, Malik KA, Ah Kang S, Kim HY. Probiotics and their fermented food products are beneficial for health. J ApplMicrobiol 2006; 100:1171-85.

16. Pradeep K, Kuttappa MA, Prasana KR. Probiotics and oral health: An update. SADJ 2014; 69:20-4.

17. Caglar E, Kavaloglu SC, Kuscu OO, Sandalli N, Holgerson PL, Twetman S. Effect of chewing gums containing xylitol or probiotic bacteria on salivary mutans streptococci and lactobacilli. Clin Oral Investig 2007; 11:425-9.

18. Montalto M, Vastola M, Marigo L, Covino M, Graziosetto R, Curigliano V, et al. Probiotic treatment increases salivary counts of lactobacilli: A double-blind, randomized, controlled study. Digestion 2004; 69:53-6.
19. Krasse P, Carlsson B, Dahl C, Paulsson A, Nilsson A, Sinkiewicz G. Decreased gum bleeding and reduced gingivitis by the probiotic Lactobacillus reuteri. Swed Dent J 2006; 30:55-60.

20. Persson GR. Immune responses and vaccination against periodontal infections. J ClinPeriodontol 2005; 32Suppl 6:39-53.

21. Volozhin AI, Il'in VK, MaksimovskiiIuM, Sidorenko AB, Istranov LP, Tsarev VN, et al. Development and use of periodontal dressing of collagen and Lactobacillus casei 37 cell suspension in combined treatment of periodontal disease of inflammatory origin (a microbiological study). Stomatologiia (Mosk) 2004; 83:6-8.

22. Flichy-Fernández AJ, Alegre-Domingo T, Peñarrocha-Oltra D, Peñarrocha-Diago M. Probiotic treatment in the oral cavity: An update. Medicina Oral Patologia Oral CirugiaBucal. 2010; 15:67780.

23. Jain P, Sharma P. Probiotics and their efficacy in improving oral health: A review. J Appl Pharm Sci 2012; 2:151-63.

24. Babaji P, Keswani K, Lau H, Lau M, Sharma N, Punga R. Role of probiotics in oral health: A review of the literature. J Educ Ethics Dent 2012; 2:52-5.

25. Nikawa H, Makihira S, Fukushima H, Nishimura H, Ozaki Y, Ishida $\mathrm{K}$, et al. Lactobacillus reuteri in bovine milk fermented decreases the oral carriage of mutans streptococci. Int $\mathrm{J}$ Food Microbiol 2004; 95:219-23.

26. Stamatova I, Meurman JH. Probiotics: Health benefits in the mouth. Am J Dent 2009; 22:329-38.

27. Reddy RS, Swapna LA, Ramesh T, Singh TR, Vijayalaxmi N, Lavanya R. Bacteria in oral health - Probiotics and prebiotics a review. Int J Biol Med Res 2011; 2:1226-33.

28. Gedalia I, Ionat-Bendat D, Ben-Mosheh S, Shapira L. Tooth enamel softening with a cola type drink and rehardening with hard cheese or stimulated saliva in situ. J Oral Rehabil 1991; 18:501-6.

29. Jensen ME, Wefel JS. Effects of processed cheese on human plaque $\mathrm{pH}$ and demineralization and remineralization. Am J Dent 1990; 3:217-23.

30. Näse L, Hatakka K, Savilahti E, Saxelin M, Pönkä A, Poussa T, et al. Effect of long-term consumption of a probiotic bacterium, Lactobacillus rhamnosus GG, in milk on dental caries and caries risk in children. Caries Res 2001; 35:412-20.

31. Meurman JH, Antila H, Korhonen A, Salminen S. Effect of Lactobacillus rhamnosus strain GG (ATCC 53103) on the growth of Streptococcus sobrinus in vitro. Eur J Oral Sci 1995; 103:253-8.

32. Petti S, Tarsitani G, SimonettiD'Arca A. Antibacterial activity of yoghurt against viridans streptococci in vitro. Arch Oral Biol 2008; 53:985-90. 
33. Ahola AJ, Yli-Knuuttila H, Suomalainen T, Poussa T, Ahlström A, Meurman JH, et al. Short-term consumption of probioticcontaining cheese and its effect on dental caries risk factors. Arch Oral Biol 2002; 47:799-804.

34. Shringeri PI, Fareed N, Battur H, Khanagar S. Role of probiotics in the treatment and prevention of oral malodor/halitosis: A systematic review. J Indian Assoc Public Health Dent 2019; $17: 90-6$

35. Reid G; Food and Agricultural Organization of the United Nation and the WHO. The importance of guidelines in the development and application of probiotics. Curr Pharm Des 2005; 11:11-6.

36. Gill H, Prasad J. Probiotics, immunomodulation, and health benefits. In: Bioactive Components of Milk. New York: Springer; 2008. p. 423-54.

37. Fuller R. Probiotics: An overview. In: Human Health. London: Springer; 1994. p. 63-73.

38. Bonifait L, Chandad F, Grenier D. Probiotics for oral health: Myth or reality? J Can Dent Assoc 2009; 75:585-90.

39. Comelli EM, Guggenheim B, Stingele F, Neeser JR. Selection of dairy bacterial strains as probiotics for oral health. Eur J Oral Sci 2002; 110:218-24.

40.Suzuki N, Tanabe K, Takeshita T, Yoneda M, Iwamoto T, Oshiro $\mathrm{S}$, et al. Effects of oil drops containing Lactobacillus salivarius WB21 on periodontal health and oral microbiota producing volatile sulfur compounds. J Breath Res 2012; 6:017106.

41. Burton JP, Chilcott CN, Tagg JR. The rationale and potential for the reduction of oral malodour using Streptococcus salivarius probiotics. Oral Dis 2005; 11Suppl 1:29-31.

42. Reid G, Jass J, Sebulsky MT, McCormick JK. Potential uses of probiotics in clinical practice. ClinMicrobiol Rev 2003; 16:658-72.

43. Bernaola Aponte G, BadaMancilla CA, Carreazo NY, Rojas Galarza RA. Probiotics for treating persistent diarrhoea in children. Cochrane Database of Systematic Reviews 2013 ;( 8):CD007401.

44. Goldenberg JZ, Yap C, Lytvyn L, Lo CK, Beardsley J, Mertz $\mathrm{D}$, et al. Probiotics for the prevention of Clostridium difficileassociated diarrhea in adults and children. Cochrane Database of Systematic Reviews 2017 ;(12):CD006095.

45. Hao Q, Dong BR, Wu T. Probiotics for preventing acute upper respiratory tract infections. Cochrane Database of Systematic Reviews 2015 ;(2):CD006895.

46. Stamatova I, Meurman JH. Probiotics and periodontal disease. Periodontol 2000 2009; 51:141-51.

47. Bhushan J, Chachra S. Probiotics-their role in prevention of dental caries. J Oral Health Comm Dent 2010; 4:78-82.

48. Yanine N, Araya I, Brignardello-Petersen R, Carrasco-Labra A, González A, Preciado A, et al. Effects of probiotics in periodontal diseases: A systematic review. Clin Oral Investig 2013; 17:1627-34.

49. Kazor CE, Mitchell PM, Lee AM, Stokes LN, Loesche WJ, Dewhirst FE, et al. Diversity of bacterial populations on the tongue dorsa of patients with halitosis and healthy patients. J ClinMicrobiol 2003; 41:558-63.

50. Loesche WJ, Kazor C. Microbiology and treatment of halitosis. Periodontol 2000 2002; 28:256-79.

51. De Boever EH, Loesche WJ. Assessing the contribution of anaerobic microflora of the tongue to oral malodor. J Am Dent Assoc 1995; 126:1384-93.

52. Outhouse TL, Fedorowicz Z, Keenan JV, Al-Alawi R. A cochrane systematic review finds tongue scrapers have short-term efficacy in controlling halitosis. Gen Dent 2006; 54:352-9.

53. Quirynen M, Avontroodt P, Soers C, Zhao H, Pauwels M, Coucke W, et al. The efficacy of amine fluoride/stannous fluoride in the suppression of morning breath odour. J ClinPeriodontol 2002; 29:944-54.

54. McBain AJ, Bartolo RG, Catrenich CE, Charbonneau D, Ledder RG, Gilbert P. Effects of a chlorhexidinegluconatecontaining mouthwash on the vitality and antimicrobial susceptibility ofin vitro oral bacterial ecosystems. Appl Environ Microbiol 2003; 69:4770-6.

55. Meurman JH, Stamatova I. Probiotics: Contributions to oral health. Oral Dis 2007; 13:443-51.

56. Burton JP, Chilcott CN, Moore CJ, Speiser G, Tagg JR. A preliminary study of the effect of probiotic Streptococcus salivarius K12 on oral malodour parameters. J ApplMicrobiol 2006; 100:754-64.

57. Iwamoto T, Suzuki N, Tanabe K, Takeshita T, Hirofuji T. Effects of probiotic Lactobacillus salivarius WB21 on halitosis and oral health: An open-label pilot trial. Oral Surg Oral Med Oral Pathol Oral RadiolEndod 2010; 110:201-8.

58. Kang MS, Kim BG, Chung J, Lee HC, Oh JS. Inhibitory effect of Weissellacibaria isolates on the production of volatile sulphur compounds. J ClinPeriodontol 2006; 33:226-32. 59. Masdea L, Kulik EM, Hauser-Gerspach I, Ramseier AM, Filippi A, Waltimo T. Antimicrobial activity of Streptococcus salivarius K12 on bacteria involved in oral malodour. Arch Oral Biol 2012; $57: 1041-7$.

59. Sutula J, Coulthwaite LA, Thomas LV, Verran J. The effect of a commercial probiotic drink containing Lactobacillus casei strain Shirota on oral health in healthy dentate people. MicrobEcol Health Dis 2013; 24:21003. 
60. Lee SH, Baek DH. Effects of Streptococcus thermophilus on volatile sulfur compounds produced by Porphyromonasgingivalis. Arch Oral Biol 2014; 59:1205-10.

61. Suzuki N, Higuchi T, Nakajima M, Fujimoto A, Morita H, Yoneda M, et al. Inhibitory effect of Enterococcus faecium WB2000 on volatile sulfur compound production by Porphyromonasgingivalis. Int J Dent 2016; 2016:8241681.

62. Moon JE, Moon YM, Cho JW. The effect of Streptococcus salivarius K12 against Prevotellaintermedia on the reduction of oral malodor. Int J ClinPrev Dent 2016; 12:153-61.

63. Reddy RS, Swapna LA, Ramesh T, Singh TR, Vijayalaxmi N, Lavanya R. Bacteria in Oral Health - Probiotics and Prebiotics A Review. Int J Biol Med Res 2011; 2:1226-33.

64. Narang S Gupta R, Narang A. Probitics in oral health care- A review. Int J SciEng Res 2011; 2:1-5.

65. Grajek W, Olejnik A, Sip A. Probiotics, 'Prebiotics and antioxidants as functional foods. ActaBiochim Pol 2005; 52:6

66. Saraf K, Shashikanth MC, Priya T, Sultana N, Chaitanya NC. Probitics - Do they have role in medicine and dentistry? J Assoc Physicians India 2010; 58:488-92.
67. Gueimonde M, Salminen S. New methods for selecting and evaluating probiotics. Dig Liver Dis. 2006; 38(Suppl 2):S242-7.

68. Sanders ME. Probiotics: definition, sources, selection, and uses. Clin Infect Dis. 2008; 46Suppl 2:S58-61; discussion S14451.

69. Reid G, Jass J, Sebulsky MT, McCormick JK. Potential uses of probiotics in clinical practice. ClinMicrobiol Rev. 2003; 16(4):658-72.

70. Meurman JH. Probiotics: do they have a role in oral medicine and dentistry? Eur J Oral Sci. 2005; 113(3):188-96.

72. Erickson KL, Hubbard NE. Probiotic immunomodulation in health and disease. J Nutr. 2000; 130(2S Suppl):403S-409S.

73. Chau CF, Wu SH, Yen GC 2007 The Development of Regulations for Food Nanotechnology. Trends food sci. Technol. 18269280

74. SozerN.KokiniJ.L. 2009 Nanotechnology and its Applications in the Food Sector. Trends biotechnol.27 8289.

Cite This Article As: Jamkhande A, Kakade S,

Gundawar A. Probiotics and oral health: a review.

SJCMDS 2021; 1(1): 14-20 